\title{
The Circular Economy at Enel $X^{*}$
}

\author{
Nicola Tagliafierro**
}

\begin{abstract}
Enel $X$ is leading the transition toward a sustainable business model, with the circular economy as an important pillar. Using renewable energy sources and materials, extending product life cycles, creating sharing platforms, reuse and regeneration, rethinking products as services.

The principles of the circular economy have become essential, considering the paradigm shift overturning the traditional linear economic model. Enel X was one of the first businesses to offer products on the market that concretely apply the five business models of the circular economy and reconsider the entire value chain from a sustainability perspective. This approach is characterized by two core principles:

1. the first, addressed internally, focuses on the business's product portfolio, which ranges from "measuring" circularity to identifying solutions for improvement;

2. the second is directed toward the outside, and especially toward industrial customers and public administrations or end customers, with the goal of evaluating their level of "circularity" and helping them outline a roadmap to circularity.
\end{abstract}

Keywords: Renewable Energy Sources; Enel X Circular Economy Score; Circular Boosting Program; Sustainability Value Chain; Scale of Circularity; Global Markets

\section{The Circular Economy at Enel X}

Using renewable energy sources and materials, extending the useful life of a product, creating platforms for sharing, reuse and regeneration, re-imagining products as services. This is the Circular Economy, a model created to meet the planet's demand for sustainability, which is a tremendous opportunity for companies in terms of competitiveness, innovation and employment, creating value for both themselves and their customers. This awareness has guided the Enel transition over the years towards a sustainable business model, an important pillar of which is our focus on the circular economy.

Enel's commitment is pursued through specific investments to develop distribution networks (to make them digital, more resilient and flexible and to enable new services); and increase energy production from renewable sources with the aim of electrifying consumption for greater decarbonisation. It also invests in the development of electric mobility (public transport, recharging infrastructure) with a positive impact on people's lives, cutting emissions and average travel times, and in

\footnotetext{
* Invited Article

** Head of Sustainability, Enel X (nicola.tagliafierro@enel.com)
} 
developing products for energy efficiency to help improve buildings' energy performance.

As demonstrated by a study in 2017 by the Ellen MacArthur Foundation, two-thirds of the world's energy is consumed in cities which alone generate nearly $70 \%$ of global emissions. These are human activities that affect climate by causing heat waves, floods and prolonged drought, with an impact on health and safety. The outlook is rather alarming, yet urban centres can be the starting point of a transition towards a new vision.

To address the issue of the cities of tomorrow, Enel has decided to use the concept of circular city since it believes it is important to take a holistic view of the urban environment, considering all its areas, with technology serving as an enabler to implement a sustainable development model and not an end in itself. With this in mind, the circular economy is an overall framework where lines of action can be established with an integrated approach.

Most of Enel's operations are concentrated in the urban context; therefore, it is a strategic priority to develop an organic and long-term vision of "future cities" in which to position its own contribution. On one hand, this implies systematically rethinking its offer, while developing new solutions, and on the other, progressively integrating the many initiatives already being pursued both at the end-product and end-service level and in production processes.

The premise of Enel's "circular vision" is based on:

- electrification of consumption (electric car, heat pumps, etc.);

- penetration of renewable energy;

- flexibility (demand-side management, etc.);

- grid technologies (smart meters, smart grids, etc.).

Enel's approach to the circular economy was set out at strategic and corporate level and then developed within the various group divisions, along the entire value chain: customers, businesses, partners and suppliers. It is a key topic when interacting with customers, who are now more aware and conscious than ever. The company's commitment ties in with the various business areas dedicated to the end customer, both in the energy market and in terms of Enel X - the Group division dedicated to new technologies for transforming energy into new opportunities.).

\section{Circular Economy at the Heart of Enel X}

Enel $\mathrm{X}$ was the first service provider to offer the market a concrete application in the context of the circular economy, such as the electric vehicle charging service.

To achieve this, the company re-imagined the entire production value chain based on the five pillars of the circular economy, which translate into five business models.

Charging stations and terminals for next-generation electric vehicles from the Juice range, for example, are the result of the "service as a product" and "sharing" model, whereby customers are given access to use of goods, shared with other users, with no transfer of ownership, thereby maximising their utilisation rate and useful life.

The "circular supply chain" model encourages the use of energy and renewable materials and underpins technologies such as adaptive street lighting systems which, thanks to artificial intelligence, can automatically adjust light output depending on 
weather conditions, traffic and luminescence, resulting in significant energy and cost savings for public bodies.

The modular solutions offered by Enel $\mathrm{X}$ were designed to facilitate the replacement, reuse or regeneration of the various components, as well as the recycling of modules at the end of their life cycle, which make up two pillars of the circular economy: "extending the life cycle of goods" and recovering the value of those being disposed of".

These are just a few examples of the many solutions already developed by Enel $\mathrm{X}$ to increase the circularity and sustainability of our economy. An ecosystem has been created to enable the Enel Group division to work with startups, research centres, universities and clients to open up our product innovations to various entities. A hyper-connected and cross-cutting sharing system of ideas, needs and solutions, which are tested and then offered internationally. A process of ongoing innovation which has also been incorporated into business processes.

To promote this new paradigm, Enel $\mathrm{X}$ has reinterpreted the entire value generation chain - from raw material suppliers to the finished product or service through to the customer - considering the economic impacts as well as the social and environmental ones.

A "scale of circularity" - the Enel X Score - was put in place to measure the degree of sustainability of our solutions, with the aim of providing our customers and suppliers with a transparency tool and making them aware of the fact that adopting circular models has benefits in terms of sustainability as well as higher savings and added value. The "scale of circularity" - ranging from a minimum of 1 to a maximum of 5 - assesses the extent to which our solutions apply the pillars of circularity and the 5 key dimensions identified by Enel X.

A fundamental part of this assessment includes elements such as: the use of recyclable, recycled or biodegradable materials and those from renewable resources; sharing-based means of use; efficiency and reuse of goods; recovering materials at the end of their lifespan.

Applied to the Enel X solutions, this assessment method generates a sustainability level label, validated by RINA, which raises both customers' environmental awareness and our efforts to continuously improve our offer and circularity level. It is a virtuous model that the company is replicating externally too.

Enel X offers an innovative Report which measures the level of energy circularity of companies and cities, which has already been tested successfully on a number of industrial customers and public bodies. In fact, a detailed Report is universally available on the degree of circularity of their businesses with a roadmap for guided and structured improvements.

\section{Enel X Circular Boosting Program}

Enel X currently serves as a booster of circularity within the new ecosystem of suppliers and customers, where it has forged an innovative and unique role in the market. Stemming from this idea, the Circular Economy Boosting Program was created to raise both the level of circularity of the company's solutions, and that one of its customers, companies and public bodies. There are essentially four phases to the programme: 
Scoring: this is key to implementing solutions that can lead to circular improvement, and measure and assess the level of circularity. To measure the circularity of Enel X solutions, a circular economy score is consolidated by using and integrating Enel's CirculAbility (C) model. In terms of customer circularity, we have developed two brand new assessments: the circularity report for industrial customers and the circularity report for public bodies. Once the perimeter of the customer or solution has been established, we can proceed to gather all data needed to calculate the base circularity level.

Boosting: Having launched the data collection process, we can move onto the boosting phase. This step helps us reconstruct the entire value chain of the solution in question, properly analyse the competitors in the local market, and scout startups and innovation through Enel's Innovation Hub. The result of this phase is a set of ideas and opportunities to be discussed with technical experts in order to select or review only the technologies and business models that meet the minimum criteria of technical and commercial feasibility for Enel X. Similarly, both the circularity report for industrial customers and that for public bodies set out the key areas for improvement and a structured roadmap with ad hoc energy solutions to raise the level of circularity reached.

Implementing: First, the solutions which are deemed attractive and feasible for the company are presented and discussed with the head of the business line, who then decides which ones will go on to be developed and marketed. Second, most of the energy solutions identified and proposed in the circularity report for industrial customers and public bodies are part of the portfolio of Enel X solutions. This way, technical and customised business proposals can be presented at the customer's request.

Re-scoring: To conclude the process, the new circular economy score can be calculated if all solutions and planning proposals were to be implemented, by measuring the achievable circular improvement. For customers, both reports provide a preview of the potential boost to circularity which can be achieved by implementing some of the suggested energy solutions. Yet, to measure the real improvement, Enel $\mathrm{X}$ customers must undergo annual assessments.

\section{Enel X Circular Economy Score}

The programme starts by measuring the current level of circularity through the Circular Economy Score for the portfolio of solutions offered, and the Site Energy Circularity Assessment for customers. The initial situation assessment is then followed by a robust method for identifying all opportunities for boosting circularity.

The score is calculated by cross-referencing the 5 business models of the Circular Economy with the 5 key dimensions of Enel X (Figure 1):

- suppliers' commitment to following the principles of the Circular Economy during the production process;

- the presence of reusable elements to facilitate the circular consumption model, thereby increasing the product's lifespan;

- the dissemination of best practices to boost efficiency in the use of resources;

- end-of-life management of products with innovative; 
- sustainable methods to encourage the reuse of materials and foster environmental awareness, engaging suppliers in virtuous mechanisms. By crossreferencing these 5 dimensions with the 5 business models of circularity.

Figure 1: Circular Economy Business Models

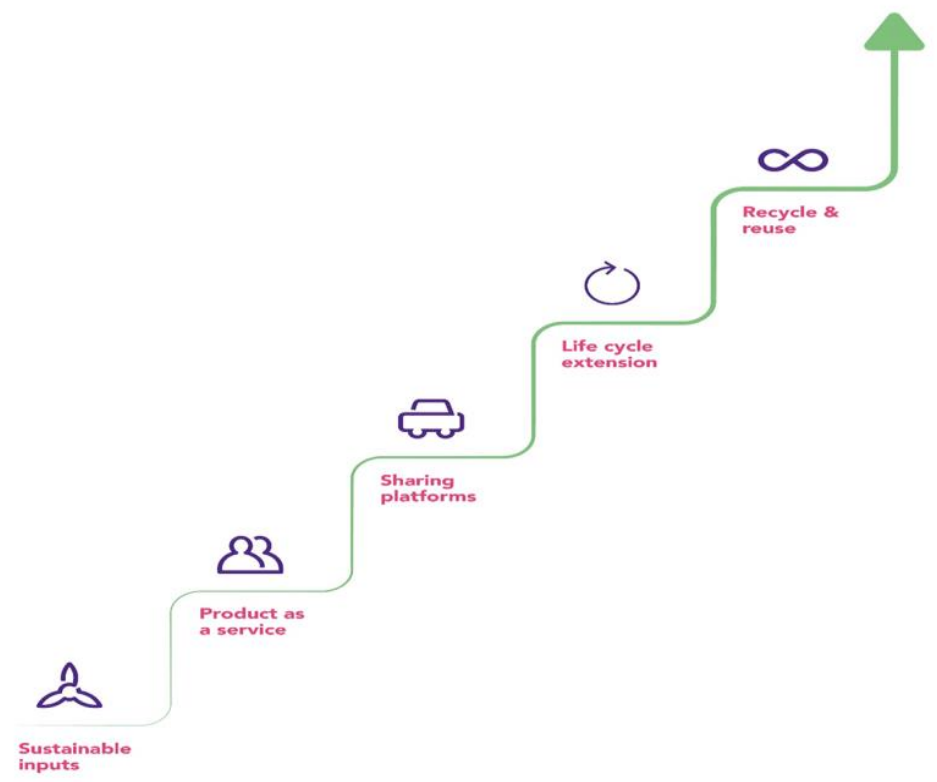

1. Sustainability in resources: The first business model proposed is based on a circular supplier chain to ensure renewable energy and raw materials of biological origin which are fully recyclable, biodegradable or recycled. How is Enel $\mathrm{X}$ contributing to this paradigm? Through our innovative solutions to generate renewable energy, for example, and with services such as Enel X Demand Response, which enables commercial and industrial consumers to be paid in exchange for their willingness to adjust their own consumption at the energy operator's request. This way, we can fulfil peaks in supply/demand and ensure greater flexibility and network stability. Demand Response promotes greater use of sources such as wind and solar, encouraging consumption during periods when energy production from these sources is higher or disincentivising them where it is lower. This means we can reduce surpluses and wastage in the generation of this type of energy, which must be consumed immediately or stored, otherwise it is lost. According to the International Energy Agency (IEA), a greater use of storage systems and digitised Demand Response could decrease renewable energy losses from $7 \%$ to $1.6 \%$ by 2040 , lowering carbon dioxide emissions by 30 million tons.

2. Product as a service: Customers have access to the goods, but they remain the property of the company which oversees their management and maintenance. This encourages manufacturers and service providers to offer longer-lasting solutions, reducing the resources used. The charging systems for electric vehicles like the 3G Pole Station and next-generation solutions from the Juice Range are just one example of how Enel $\mathrm{X}$ applies this paradigm in real terms. 
The customer only pays what they need (recharging service), without having to buy the product (i.e. the recharging infrastructure). This is a sustainable model that fulfils the new consumption habits of millennials (those born in the late ' $80 \mathrm{~s}$ and early '90s) and Generation Z (those born after 1997), who seem to prefer possession of goods and having the experience of ownership.

3. Sharing platforms: Sharing makes it possible to reduce the amount of products in circulation, as well as the resources needed to produce them and the energy consumed to run them, giving customers substantial savings and, for some applications, even profits. The model is applied by the Vehicle-to-Grid (V2G) bidirectional charging infrastructure, which Enel X uses for electric cars, transforming each user into a potential energy supplier. This infrastructure makes it possible to integrate electric cars within the grid (e.g. when they are parked at a charging station in the garage and connected to the grid) to serve as energy suppliers through Enel X's Demand Response service. This sets in motion a virtuous circle that lowers the cost of using electric vehicles for customers who, in turn, are rewarded for their contribution to the grid, and helps to disseminate a zero-impact mobility model. The business model of sharing is also applied to solutions that bring together multiple services for the customer in the same asset. This is the case of the Enel X Juice Lamp - an intelligent LED streetlight which integrates public lighting and the electric recharging infrastructure. In addition to recharging two cars at the same time, this system can be set up for video surveillance, air quality monitoring and fibre connectivity/Wi-Fi. So many different services for the community within a single fully-sustainable solution.

4. Extending life cycles: The product and its components are repaired, recycled, recovered and reused, thereby optimising its economic benefits and reducing the resources used and waste to be disposed of. Enel $\mathrm{X}$ applies this paradigm by offering its customers maintenance, repair, assistance and remote management on one hand, and solutions such as the Juice Range on the other, which have a modular design so as to be easily disassembled and regenerated to last longer.

5. Recovery and recycling: When designing its solutions, Enel $X$ takes inspiration from this model to broaden the range of alternatives as much as possible to recover the asset at the end of its life cycle. With this model in mind, Enel X has just completed a project to recover plastic from waste products to make the new charging stations for electric passenger vehicles. In fact, as of this year, the Juice Boxes will be entirely produced from recycled plastics. This is just one of the many examples of how Enel X's innovations help accelerate the adoption of means of production and consumption within the vast ecosystem of its suppliers, partners, installers and customers, and continue to further the culture of sustainability.

Enel $\mathrm{X}$ is able to calculate the Circular Economy Score with various levels of circularity (Figure 2): 
Figure 2: Circularity Scale Range

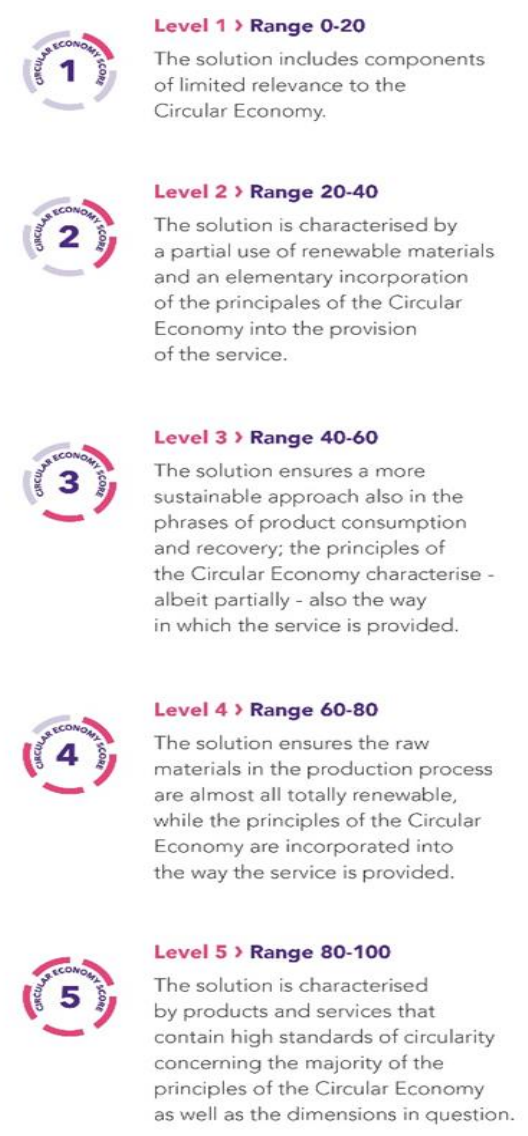

The circular economy score is the starting point for Enel X's enhancement programme. The scoring system is based on Enel's CirculAbility (C) model, which has been partially integrated to adapt better to Enel's business, focusing on three components:

1. CIRCULAR FLOW (CF) - This is a quantitative assessment of the circularity of the inputs (both material and energy) and outputs generated to manufacture a specific product;

2. CIRCULAR SALES (CS) - This makes a qualitative assessment of whether the commercial structure and configuration effectively enable circular business and consumption models;

3. CIRCULAR USE (CU) - This measures the impact that business models such as "sharing", "product as a service" and "product life cycle extension" have on the durability and/or utilisation rate of a given product.

The CF and CU components are inherited from Enel's CirculAbility (C) and account for $90 \%$ of the final score, whereas the CS component accounts for $10 \%$ and has been integrated to promote (Figure 3):

- Using digital sales channels rather than physical stores (such as limiting the need for resources and materials to build or renovate and manage physical spaces); 
- Designing and launching commercial offers with a view towards the "product as a service" configuration;

- Designing and launching commercial offers to enable sharing of the configurations;

- Supply of life cycle extension services;

- Supply of end-of-life collection to facilitate recovery and reuse;

- Implementation of consumer awareness initiatives.

Figure 3: Enel X's Circular Economy Score

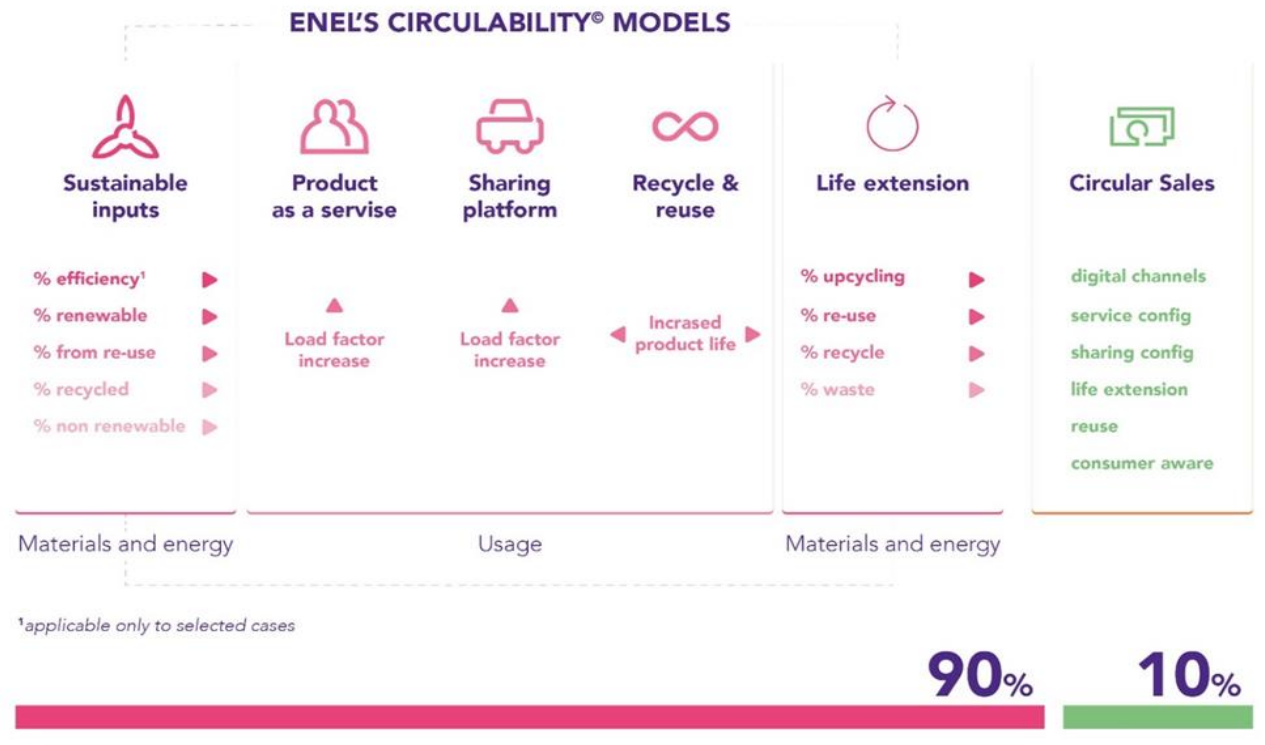

These three components cover all 5 of the Circular Economy business models exhaustively, answering the following key questions respectively:

- "How is this product made?"

- How is it sold by the company?

- How do consumers use it?

To answer all these questions, it is essential to do onboarding and have cooperation with suppliers to access all information needed to calculate the circular economy score of a given product. The aim is to create a means of providing transparency to our customers and suppliers, making them aware of the fact that the adoption of circular models provides benefits in terms of sustainability, cost-savings and added value.

\section{Circularity of Enel X Solutions}

Demand Response: Enel X offers commercial and industrial consumers an innovative service to give them access to flexibility markets. The service modulates the customer's power consumption in response to peaks in energy demand and supply. This improves the flexibility and stability of the network, providing 
customers with the highest possible financial return. The Demand Response service provided by Enel X fulfils 2 out of the 5 circular economy business models:

- Sustainable inputs: this manages the unpredictability and intermittency of renewable energy, thereby increasing integration and making the network reliable and flexible.

- Sharing platform: Demand Response makes it possible to adjust energy demand rather than supply, so that customers can share their spare capacity and make it available to the grid.

The level of circularity of Demand Response varies from country to country and from customer to customer, so no universal score can be applied. Once a customer activates the DR programmes, the score can be calculated with indicators that take account of these variables. The response to the question has the potential to achieve a score of 5 .

Street Lighting: By applying circular economy models, Enel X designs and manufactures a wide range of solutions for cities to improve sustainability and innovation. The Enel X public lighting solutions fulfil 3 out of the 5 circular economy business models:

- Sustainable inputs - Use of materials and technologies to provide higher efficiency and energy savings using LEDs rather than traditional lighting.

- Sharing platform - Using the same resource for various functions, from surveillance cameras through to the charging infrastructure

- Product as a service - As a service provider, Enel X offers products for use by customers in the form of public lighting.

On the scale of circularity of Enel X solutions, the smart lighting range has a score of 4. The solution is based on almost entirely renewable raw materials in the production process, integrating the principles of circular economy into the way the service is provided.

Condensing Boilers: Enel X offers customers a wide range of condensing boilers - a product that fulfils various principles of the circular economy. These boilers recover heat from exhaust gases, thereby reducing energy consumption, and have a lower environmental impact thanks to condensation technology. The Enel $\mathrm{X}$ condensing boiler meets 2 out of 5 circular economy business models:

- Sustainable inputs - About $40 \%$ of the steel components used to build the boiler come from recycled inputs.

- Recycling and reuse: Only 1\% of the aluminium and plastic used in the production process becomes waste and is entirely sent for recycling.

Based on the circularity scale for Enel X solutions, the condensing boiler achieves a score of 4 . The solution combines a production process that uses raw materials which are almost entirely renewable and a service integrated with circular economy principles.

Photovoltaics: The residential PV systems offered by Enel X are a consolidated, sustainable and affordable solution to autonomously produce energy for domestic needs. Photovoltaic systems ensure energy circularity by providing greater energy efficiency compared to drawing from the grid, thereby reducing the environmental 
impact and $\mathrm{CO}_{2}$ production, with energy consumption from renewable sources instead of fossil fuels. The Enel X photovoltaic option fulfils 2 out of 5 circular economy business models:

- Sustainable inputs - Photovoltaic systems are by nature renewable and $12 \%$ of the materials used to produce them come from recycled inputs.

- Recycle and reuse - Only $1 \%$ of all materials used in the production process becomes waste and is entirely sent to be recycled.

Based on the circularity scale for Enel $\mathrm{X}$ solutions, the photovoltaic solution achieves a score of 3 . This solution also ensures sustainability in the phases of consumption and product recovery, and the service is partially integrated with the principles of circular economy.

Photovoltaics and Storage: The Enel X photovoltaic and storage systems are an energy production solution for domestic energy needs. This solution fulfils 2 out of 5 circular economy business models:

- Sustainable inputs - Photovoltaic systems are by nature renewable and $12 \%$ of the materials used to produce them come from recycled inputs. Storage systems are key to increasing domestic energy consumption from renewable resources and over $15 \%$ of the materials used to produce the systems come from recycled inputs (copper, aluminium and steel).

- Recycle and reuse - Only $1 \%$ of all materials used in the production process becomes waste and is entirely sent to be recycled. However, the recovered material may not be re-used to make new batteries, so Enel $\mathrm{X}$ is committed to finding ways to further increase their recyclability.

Based on the circularity scale for Enel X solutions, the Enel X photovoltaic system solutions achieved a score of 3 . This solution also ensures sustainability in the phases of consumption and product recovery, and the service is partially integrated with the principles of circular economy.

Storage: Enel X energy storage stockpiles excess energy produced by photovoltaic systems. This increases the grid's autonomy and domestic energy, as well as the selfconsumption of energy produced by the photovoltaic system and other renewable sources. Enel X storage meets 2 out of 5 circular economy business models:

- Sustainable inputs - About $15 \%$ of the materials used to build the solutions come from recycled inputs. Storage systems are essential to increasing household energy consumption from renewable resources.

- Recycling and reuse - Only $1 \%$ of all materials used in the production process becomes waste and is entirely sent to be recycled.

Based on the circularity scale for Enel X solutions, Enel X storage systems gained a score of 3. This solution also ensures sustainability in the phases of consumption and product recovery, and the service is partially integrated with the principles of circular economy.

Solar Thermal Energy: Enel X has chosen to include solar thermal energy in its range of products with a view towards circularity. This system enables the direct conversion of solar energy into thermal energy and, thanks to its efficiency, it increases the value and energy class of the home, making it partially energyautonomous. It also provides savings by using solar energy to heat water and the 
home. The Enel X solar thermal solution fulfils 2 out of 5 circular economy business models:

- Sustainable Inputs - Harnessing solar energy reduces CO2 emissions. Moreover, $31 \%$ of the materials used to build the solution come from recycled inputs.

- Recycling and reuse - At the end of their life cycle, over $90 \%$ of the glass, polyurethane and steel components are collected and recycled.

Based on the circularity scale for Enel X solutions, the Enel X solar thermal solution achieves a score of 3 . This solution also ensures sustainability in the phases of consumption and product recovery, and the service is partially integrated with the principles of circular economy.

JuicePole: JuicePole Enel $\mathrm{X}$ is a solution for outdoor charging, designed for the urban environment and public use. It is a shared resource and allows you to charge two electric vehicles simultaneously. Enel X JuicePole fulfils 4 out of 5 circular economy business models:

- Sustainable inputs - Of the entire JuicePole production cycle, around $30 \%$ of the energy used comes from renewable sources, considering the energy mix of countries which manufacture the components and the presence of selfgeneration energy systems from renewable sources.

- Product as a service - Enel X makes its infrastructure available to other contracted providers, who can use public JuicePoles to offer charging services through their apps.

- Sharing platform - The JuicePass app allows end users to share the resource to optimise utilisation

- Life cycle extension - To renew the charging point technology, Enel X recovers all of the parts which are still functioning and reuses them for maintenance.

Based on the circularity scale for Enel X solutions, JuicePole achieves a score of 3. This solution also ensures sustainability in the phases of consumption and product recovery, and the service is partially integrated with the principles of circular economy.

\section{Enel X Circular Economy Report}

"Enel X aims to increase not only the level of circular maturity of products and services, through the Circular Economy Score illustrated in the previous paragraph, but also that of its customers, meaning companies and public bodies.

To do this, Enel X has developed the Circular Economy Report. This is a method whereby Enel $\mathrm{X}$ identifies the circularity level of the company or city and proposes the most suitable solutions to support their improvement process.

The Report is based on an algorithm certified by an external body, and helps develop a roadmap for improving the circularity level identified. This gives the company or public body greater awareness of their energy performance, with the ability to identify new savings and efficiency opportunities, as well as to release communications with a greater impact to stakeholders about the efforts they are making in terms of sustainability and circular economy (Figure 4).

The Circular Economy Report is made up of three sections: 
1. Assessment: Analysis at two maturity levels of the customer in terms of the circular economy:

a) City (in the case of public bodies) or Corporate (in the case of industrial clients) Assessment;

b) Site specific - Energy Assessment.

2. Roadmap: Structured path of actions to raise the base level of circularity.

3. Sensitivity analysis: To assess the percentage increase of the circularity level based on the circular solutions suggested in the roadmap.

Figure 4: Circular Economy Boosting Program

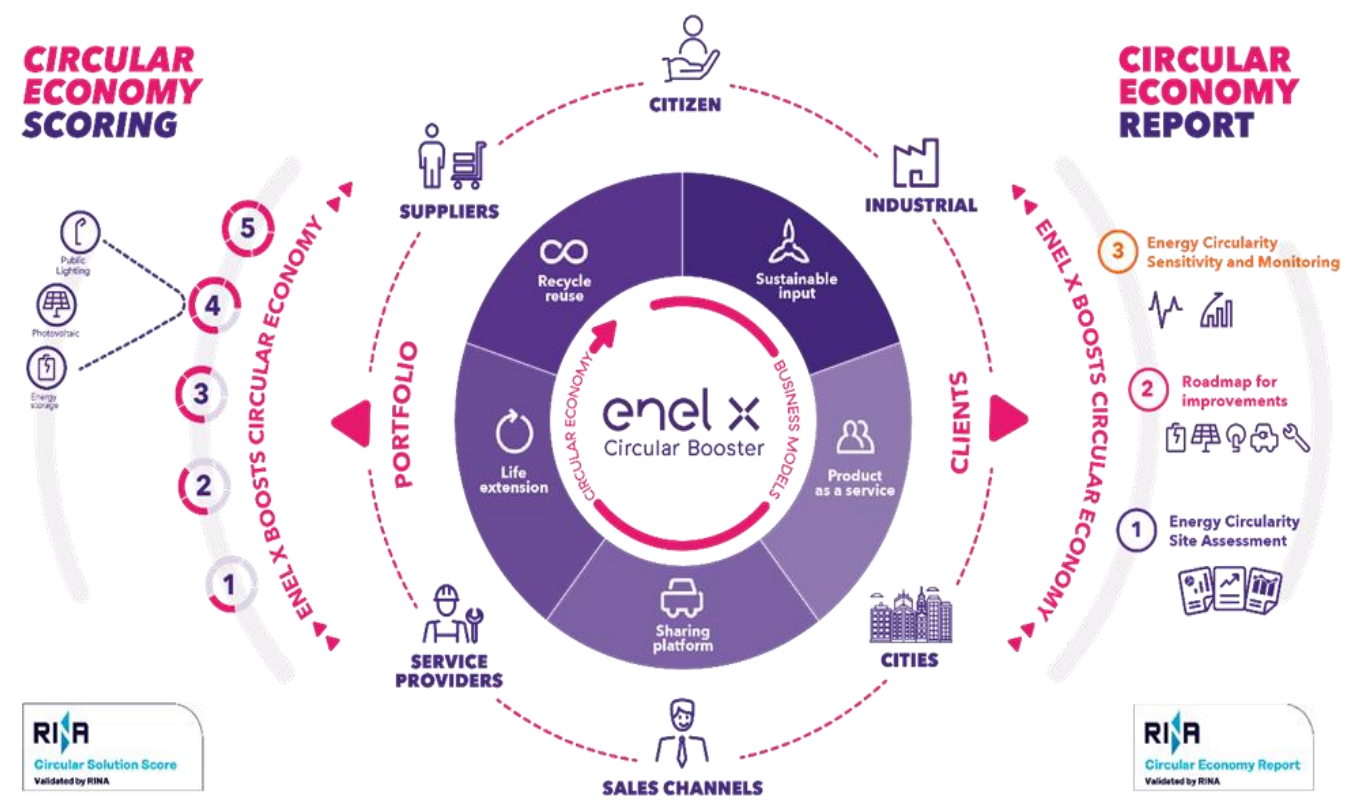

\section{Circular Economy Report for Companies and Public Bodies}

Enel X draws up a detailed report for companies and public bodies - the Circular Economy Report -, which identifies the current level of circularity and proposes a roadmap of innovative solutions in order to raise it (Figure 5).

For businesses, the report consists of a Corporate Circular Economy Assessment made up of a qualitative analysis, assessing the company's all-round level of circularity from their design and procurement policies through to waste management and a detailed Energy-Site specific Circular Economy Assessment, which is a 
quantitative analysis applied to one or more of the production/administrative sites focusing on specific aspects of production, consumption and energy management.

Figure 5: Circular Economy Client Report
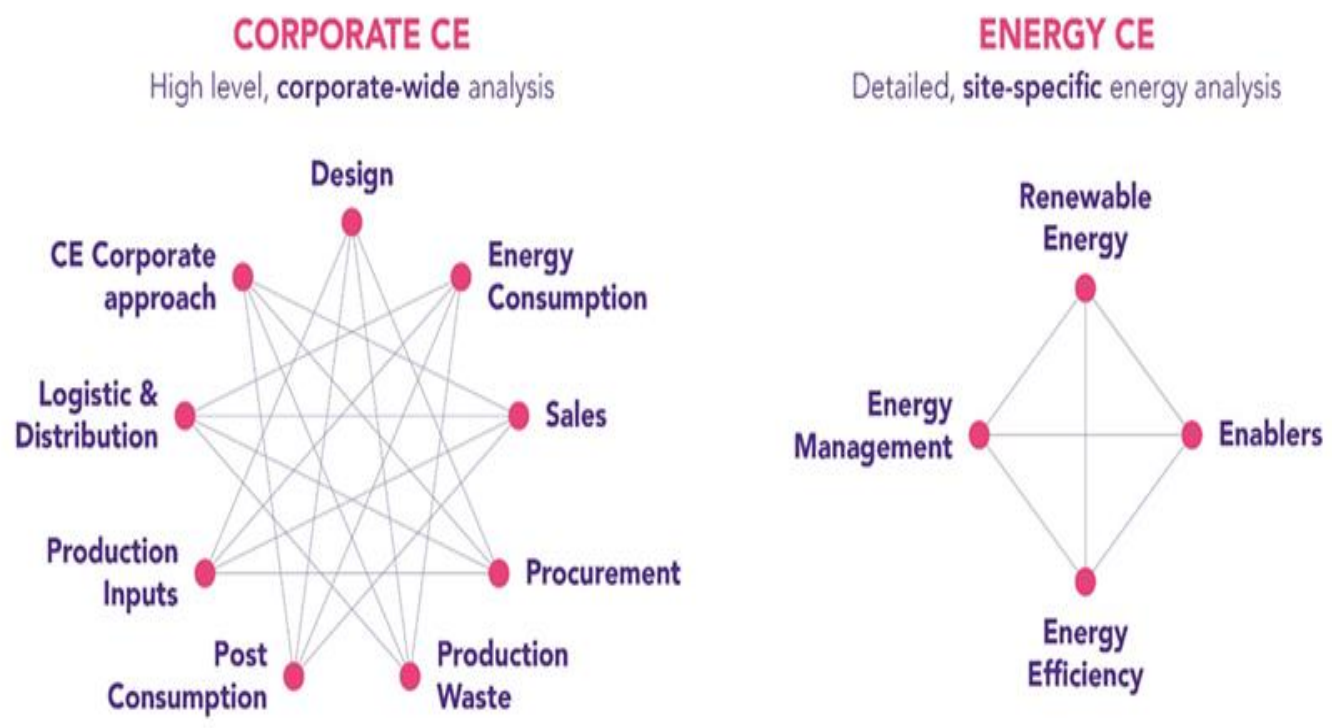

For public bodies on the other hand, the report consists of a City Circular Economy Assessment: a high-profile analysis to assess the City's level of energy circularity in the direct management of its property assets and policy guidelines. The particular areas of interest are: energy management, mobility, waste and emissions.

And an Energy-Site specific Circular Economy Assessment: a detailed quantitative analysis which is applied to a specific site in the City (e.g. school, office, gym) focusing on the analysis of electricity and thermal energy sources - in terms of consumption and generation - and on efficient energy use and energy management practices.

Once the degree of circularity of the company or public body has been established, Enel $\mathrm{X}$ uses its portfolio of more than twenty products ranging from Advice to distributed renewable energy generation and flexibility through to electric mobility, to develop a Circular Economy Energy Roadmap to raise the circularity level up to a potential of $100 \%$ through a targeted selection of the most appropriate solutions.

By way of the sensitivity analysis, Enel $\mathrm{X}$ is able to calculate the score percentage increase of the company or public body based on the number of integrated innovative solutions (Figure 6). 
Figure 6: Customized Roadmap

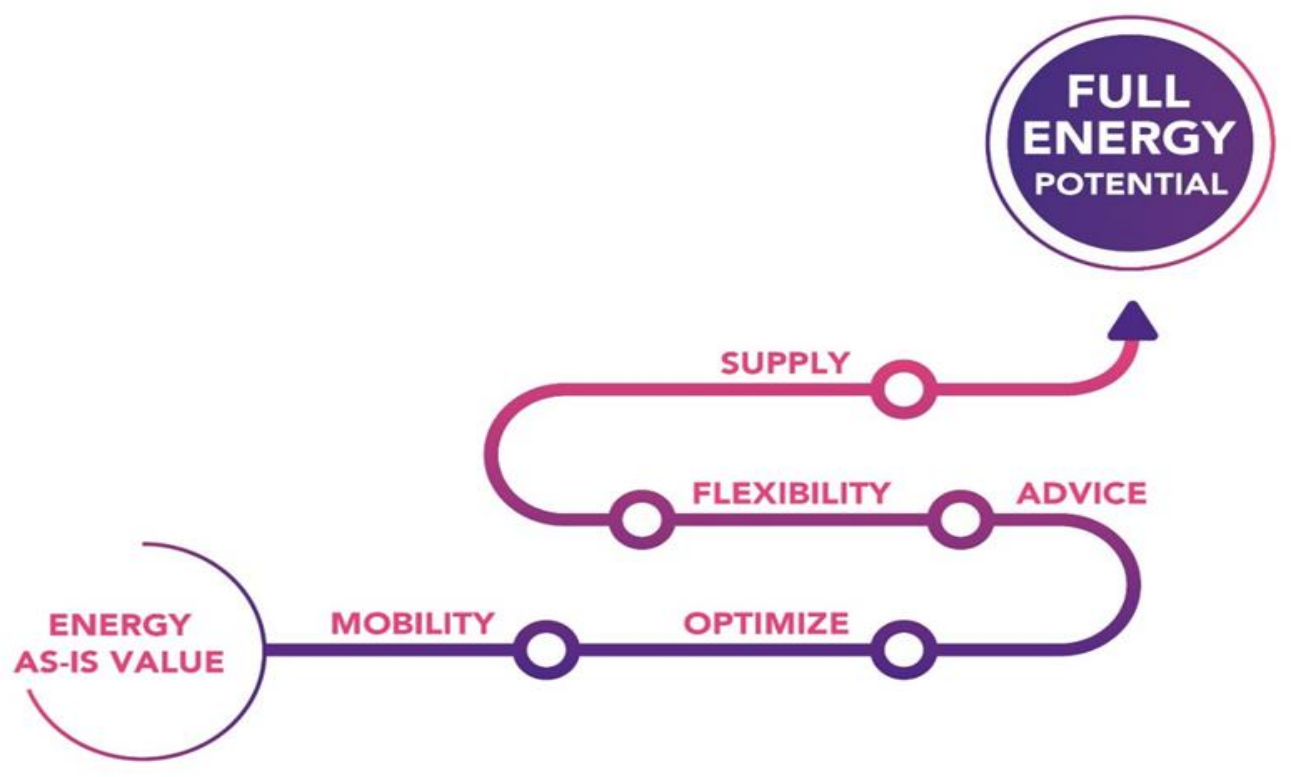

\section{Examples of Enel $X$ circular projects in the world}

Self-sufficient condo in NYC: At Marcus Garvey Village, an apartment building in the Brownsville area made up of 625 apartments, Demand Energy has developed a first-generation microgrid to make the condominium entirely self-sufficient. The microgrid integrates a solar photovoltaic system with a $400 \mathrm{~kW}$ power capacity, an energy storage of $300 \mathrm{~kW} / 1.2 \mathrm{MWh}$ and a $400 \mathrm{~kW}$ fuel cell, connected to Demand Energy DEN.OS ${ }^{\mathrm{TM}}$ smart software (Distributed Energy Network Optimization System) which manages distributed generation energy resources. A key aspect of the DEN.OS system is its ability to ensure that the condominium consumes all of the energy produced. This revolutionary project is the first residential storage experiment in New York to use lithium-ion batteries. It is a prime example of how a power grid can be developed in a large city with smart management of distributed generation resources, improving the efficiency and strength of the whole system. The system developed using Demand Energy Network software helps reduce energy costs for residents at Marcus Garvey Village, it simplifies the management of the electrical load for the local distributor, and lowers greenhouse gases. In fact, the DEN.OS smart system makes it possible to predict peaks in electricity demand and meet the load by integrating different generation sources in an optimal way.

Used batteries in Spain: In Melilla, Spain, an Enel plant is in the trial stage with used batteries that are no longer suitable for use in electric vehicles, but can have a second life to regulate plant production.

Replacing old wood stoves with air-conditioning devices in Chile: Enel X has tabled an initiative to replace old wood stoves with air-conditioners free of charge. The benefits for the public and the environment are clear: improved air quality inside and outside the house, economic savings, and having a single device for both heating 
and cooling. Replacing stoves is one positive example among many, but it can pave the way for similar projects in other countries.

Reuse of functioning terminal components: Enel $\mathrm{X}$ has made it a mandatory requirement within the tender for maintainers to reuse working components from electric charging columns. In practical terms, where a malfunction occurs and the technician is not able to make the repair remotely, they have to go to the site and replace the faulty column with a working one. They then bring the broken one into stock and recover any reusable components, which are then stored in the installer's warehouse for reuse in later repairs.

\section{Conclusion}

Enel is undoubtedly one the most active multinationals in the world in the area of circular economy. It has created an alliance of Italian companies to promote the exchange of best practices, develop joint projects, work with startups and research centres, and sustainably increase competitiveness in the sector in Italy. Interaction with the environment, cooperation with communities, and an open culture based on listening. To build an effective circular ecosystem, it is vital that top-down and bottom-up approaches are able to co-exist: here, institutions play a key role in encouraging infrastructure development, as do initiatives from citizens, associations and businesses. An integrated approach where circularity is engrained in a mindset where all individuals can develop their activities and choices both in private life and the public sphere. Where everyone is equipped to contribute to a new vision of the city. Evolved, shared and sustainable.

\section{Bibliography}

Becattini, G. (2004). A New Approach to Industrial Change, London: Edward Elgar Publishing.

Brondoni, S.M. (2018). Planned Obsolescence, Total Quality, Zero Defects and Global Competition. Symphonya. Emerging Issues in Management (symphonya.unicusano.it), (2), 8-20.

http://dx.doi.org/10.4468/2018.2.02brondoni

Brondoni, S. M. (2018). Competitive Business Management and Global Competition. An Introduction, in S. M. Brondoni (ed.), Competitive Business Management. A Global Perspective. AbingdonTurin: Routledge-Giappichelli.

Brondoni, S. M., \& Mosca, F. (2017). Ouverture de 'Integrated Corporate Social Responsibility', Symphonya. Emerging Issues in Management (symphonya.unimib.it), (1), 1-6.

http://dx.doi.org/10.4468/2017.1.01ouverture

Brondoni, S. M., \& Boccardelli, P. (2019). Ouverture de 'IR 4.0, Network Economies \& Stakeholder Engagement'. Symphonya. Emerging Issues in Management (symphonya.unicusano.it), (2), 1-7. http://dx.doi.org/10.4468/2019.2.01ouverture

Cassano, R. (2019). Corporate Global Responsibility and Reputation Risk Management. Symphonya. Emerging Issues in Management (symphonya.unicusano.it), (1), 129-142.

http://dx.doi.org/10.4468/2019.1.10cassano

Liedtka, J., \& Ogilvie, T. (2011). Designing for Growth: A Design Thinking Tool Kit for Managers, New York: Columbia University Press.

Ellen MacArthur Foundation (2015). Towards a Circular Economy: Business Rationale for an Accelerated Transition. 
www.ellenmacarthurfoundation.org/publications/towards-a-circular-economy-business-rationalefor-an-accelerated-transition

European Commission (2020). Circular Economy Action Plan.

https://ec.europa.eu/environment/circulareconomy/pdf/new_circular_economy_action_plan.pdf

Mosca, F., \& Civera, C. (2017). The Evolution of CSR: An Integrated Approach. Symphonya. Emerging Issues in Management (symphonya.unimib.it), (1), 16-35.

http://dx.doi.org/10.4468/2017.1.03mosca.civera

Rieple, A., Pironti, M., \& Pisano, P. (2012). Business Network Dynamics and Diffusion of Innovation, Symphonya. Emerging Issues in Management (symphonya.unimib.it), (2),13-25.

http://dx.doi.org/10.4468/2012.2.02rieple.pironti.pisano

Salvioni, D. M. (2003). Corporate governance and global responsibility. Symphonya. Emerging Issues in Management (symphonya.unimib.it), (1), 44-54.

http://dx.doi.org/10.4468/2003.1.05salvioni

Salvioni, D. M., \& Gennari, F. (2017). CSR, Sustainable Value Creation and Shareholder Relations. Symphonya. Emerging Issues in Management (symphonya.unimib.it), (1), 36-49.

http://dx.doi.org/10.4468/2017.1.04salvioni.gennari

Salvioni, D. M., Franzoni, S., Gennari, F., \& Cassano, R. (2018). Convergence in Corporate Governance Systems and Sustainability Culture. International Journal of Business Performance Management, 19, 7-15.

Salvioni, D. M., \& Gennari, F. (2019). CSR, Sustainable Value Creation and Shareholder Relations. Symphonya. Emerging Issues in Management (symphonya.unicusano.it), (1), 28-39.

http://dx.doi.org/10.4468/2017.1.04salvioni.gennari

Svensson, N., \& Funck, E. K. (2017). Management Control in Circular Economy. Exploring and Theorizing the Adaptation of Management Control to Circular Business Models. Journal of Cleaner Production, 2331, 390-398.

http://dx.doi.org/10.1016/j.jclepro.2019.06.089 